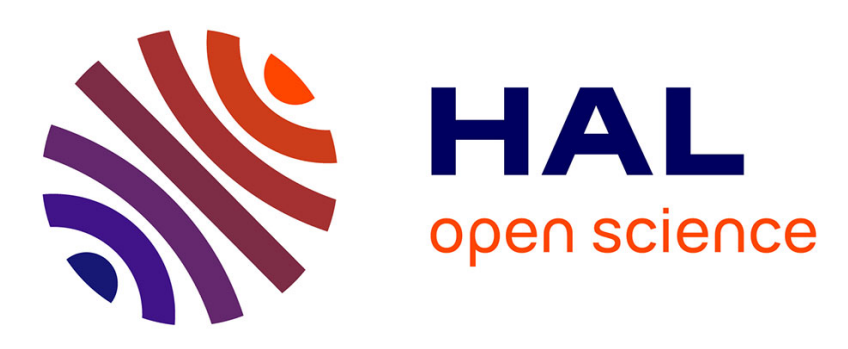

\title{
Magnetic, electric and thermal properties of cobalt ferrite nanoparticles
}

Lilia Ajroudi, Najeh Mliki, L. Bessaïs, V. Madigou, Sylvie Villain, Christine Leroux

\section{- To cite this version:}

Lilia Ajroudi, Najeh Mliki, L. Bessaïs, V. Madigou, Sylvie Villain, et al.. Magnetic, electric and thermal properties of cobalt ferrite nanoparticles. Materials Research Bulletin, 2014, 59, pp.49. 10.1016/j.materresbull.2014.06.029 . hal-01053683

\section{HAL Id: hal-01053683 \\ https://hal-univ-tln.archives-ouvertes.fr/hal-01053683}

Submitted on 1 Aug 2014

HAL is a multi-disciplinary open access archive for the deposit and dissemination of scientific research documents, whether they are published or not. The documents may come from teaching and research institutions in France or abroad, or from public or private research centers.
L'archive ouverte pluridisciplinaire $\mathbf{H A L}$, est destinée au dépôt et à la diffusion de documents scientifiques de niveau recherche, publiés ou non, émanant des établissements d'enseignement et de recherche français ou étrangers, des laboratoires publics ou privés. 


\title{
Magnetic, electric and thermal properties of cobalt ferrite nanoparticles
}

\author{
L.Ajroudi $^{\mathrm{a}}$, N. Mliki ${ }^{\mathrm{a}}$, L.Bessais $^{\mathrm{b}}, \mathrm{V}$ Madigou $^{\mathrm{c}}$, S.Villain $^{\mathrm{c}}$, Ch.Leroux $^{\mathrm{c}}$
}

a. LMOP, Faculté des Sciences de Tunis, Université de Tunis El Manar, 2092 Tunis, Tunisie

b. CMTR, ICMPE, CNRS UMR 7182, Université Paris Est, 2-8, rue H. Dunant, 94320 Thiais, France

c. IM2NP, CNRS UMR 7334, Université de Toulon, Bât.R, B.P.20132, 83957 La Garde, France

corresponding author : leroux@ univ-tln.fr, tel. +33 (0) 494142421 fax +33 (0) 494142168

lilia.ajroudi@yahoo.fr； najeh.mliki@fst.rnu.tn ; bessais@icmpe.cnrs.fr ; madigou@univ$\underline{\text { tln.fr ; villain@univ-tIn.fr }}$

Abstract

The electric and magnetic properties as well as the thermal stability of $\mathrm{Co}_{\mathrm{x}} \mathrm{Fe}_{3-\mathrm{x}} \mathrm{O}_{4}$ nanopowders, $(0.6<x<1.8)$ were investigated. These powders were synthezised using a one pot solvo-thermal route with acetylacetonates as precursors. The properties were linked to the size, morphology, composition of the particles and to the cation distribution. With the exception of $\mathrm{x}=0.6$, the powders are stable up to $600{ }^{\circ} \mathrm{C}$. Whatever the composition, $\mathrm{Co}^{2+}$ has a strong tendency to occupy tetrahedral sites, contrary to what occurs in bulk ferrites. The nanopowders display a semi conducting behaviour. Between ambient and $500{ }^{\circ} \mathrm{C}$, conduction occurs between $\mathrm{Co}^{2+} \leftrightarrow \mathrm{Fe}^{3+}$ pairs, and intergrain conduction predominates. The conductivity is in the $10^{-7} \Omega^{-1} \cdot \mathrm{cm}^{-1}$ range. The $\mathrm{Co}_{\mathrm{x}} \mathrm{Fe}_{3-\mathrm{x}} \mathrm{O}_{4}$ nanopowders behave magnetically as a superparamagnetic assembly of single-domain particles. The magnetocrystalline anisotropy constant is significantly higher for these nanoparticles than for bulk ferrites. $\mathrm{Co}_{1.8} \mathrm{Fe}_{1.2} \mathrm{O}_{4}$ 
displays the lowest blocking temperature $(200 \mathrm{~K})$ and the highest anisotropy $\left(\mathrm{K}=2110^{6}\right.$ $\left.\mathrm{erg} / \mathrm{cm}^{3}\right)$

KEYWORDS : A. oxides, B. solvothermal, magnetic properties, C. impedance spectroscopy, D. transmission electron microscopy (TEM)

\section{Introduction:}

Ferrites are materials which combine several remarkable physical properties along with chemical stability, low production cost, and have already many application fields [1]. In form of nanomaterials, ferrites may have superparamagnetic properties [2] and are currently used in magnetic data storage, magnetic imaging, drug delivery and microwave devices [3-4]. Recently, nano ferrites have shown gas sensing capability [5-6], as well as photocatalytic and catalytic activity toward the degradation of organic matters and oxidative reactions in presence of reducing gases [7-9]. This multifunctional character of ferrites has potential application in the field of sensors, transducers and actuators [10-14]. The control of the size, morphology and chemical composition of the spinel ferrite nanoparticles, should allow adjusting their various properties for specific needs.

In a previous work, the synthesis route of the $\mathrm{Co}_{\mathrm{x}} \mathrm{Fe}_{3-\mathrm{x}} \mathrm{O}_{4}$ nanoparticles and their catalytic response to methane were presented with an exhaustive structural characterization, including X-rays diffraction (XRD), transmission electron microscope (TEM) imaging and energy dispersive spectroscopy (EDS) analysis [7]. The elaboration route developed led to chemically homogeneous spinel cobalt ferrites, with mean size ranging from 4 to $7 \mathrm{~nm}$, the smallest particles being obtained for $\mathrm{x}=1.8$. The morphology study of the particles evidenced a spherical form for low cobalt content, and a very irregular shape for high cobalt content. The highest conversion rate, at a given temperature, was obtained for $\mathrm{Co}_{1.8} \mathrm{Fe}_{1.2} \mathrm{O}_{4}$. The role 
of the cation distribution and vacancies in the catalytic reaction was evidenced. The sensing properties of cobalt ferrite nanoparticles were investigated, and different resistance variations were noticed, depending on the cobalt amount $[15,16] . \mathrm{Co}_{1.8} \mathrm{Fe}_{1.2} \mathrm{O}_{4}$ showed a p-type semiconducting response to reducing gases, as $\mathrm{CoFe}_{2} \mathrm{O}_{4}$ showed n-type behaviour. Like catalytic properties, magnetic and electric conduction properties of nanoparticles, are related to the mean size, the size distribution and the shape of the particles. In case of spinels, the cation distribution on octahedral and tetrahedral sites influences physical and chemical properties. The surface state of the nanoparticles plays also an important role in catalysis reactions as well as in magnetic phenomena. It is well known that the efficiency of a catalytic conversion increases with the amount of exposed surface, which is related to the size and the shape of the particles, with the nature of the exposed cation sites, and the number and type of defects at the surface $[17,18]$. In nanostructured magnetic materials, surface effects usually lead to increased magnetization or superparamagnetism [2].Electric properties are also linked to the particle size, to the cation distribution and to the occurrence of vacancies $[19,20]$.

Our work aims to investigate the influence of the composition, particle size and cation distribution of cobalt ferrites nanopowders on their thermal, electric and magnetic properties and to determine some characteristic values. The electric, magnetic and thermal properties of nanoparticles of cobalt ferrites for various cobalt contents were characterized and related to morphology, size, crystallographic structure and composition. The composition dependence of these properties in very small nanocrystalline cobalt ferrites (less than $10 \mathrm{~nm}$ ) has not yet been studied. Electric and magnetic properties of ferrites were already investigated but for particles in the $100 \mathrm{~nm}$ range [21]. The magnetic study of very small particles was done but for a low cobalt concentration $(\mathrm{x}<0.6)$ [22]. The conductivity and Neel temperature dependence with grain size has been investigated in nanocrystalline cobalt ferrite powder for one composition only, namely $\mathrm{CoFe}_{2} \mathrm{O}_{4}$ [19-20, 23-24]. Most of the magnetic or electric 
investigations of nanoparticles of cobalt ferrites in literature concern $\mathrm{Cd}, \mathrm{Al}$ or $\mathrm{Zn}$ doped ferrites [25-27]. Magnetic properties and transport mechanisms of cobalt ferrites $\mathrm{Co}_{\mathrm{x}} \mathrm{Fe}_{3-\mathrm{x}} \mathrm{O}_{4}$ with various compositions were studied [28], but in that case the grain sizes were in the micronic range.

\section{Experimental procedures:}

\subsection{Synthesis of $\mathrm{Co}_{\mathrm{x}} \mathrm{Fe}_{3-\mathrm{x}} \mathrm{O}_{4}$ nanoparticles}

A series of cobalt ferrites nanoparticles samples with the general formula $\mathrm{Co}_{\mathrm{x}} \mathrm{Fe}_{3-\mathrm{x}} \mathrm{O}_{4}, \mathrm{x}$ varying from 0.6 to $1.8(\mathrm{x}=0.6,1,1.2$ and 1.8$)$ were synthesized by a new one-pot solvo thermal route, using acetylacatonates of iron and cobalt precursors, dissolved in benzyl alcohol. Synthesis details can be found in a previous work [7].

\subsection{Structural characterization}

The detailed structural characterization, by XRD and TEM, of the as prepared cobalt ferrites nanopowders can be found in [7], for 3 compositions. The XRD diagram were collected in a classical $\theta-2 \theta$ angles coupled mode on a D5000 Siemens Bruker diffractometer operating with a copper X-rays source and equipped with a back monochromator, to avoid fluorescence. The diagrams were collected with a step of $0.04^{\circ}$, a time of 20 s per step, over a $2 \theta$ range from 15 to $115^{\circ}$. Rietveld refinement was done using the Powdercell software. Morphologies and crystal sizes of nanoparticles were determined by TEM, using a Tecnai $200 \mathrm{kV}$, with a point to point resolution of $0.25 \mathrm{~nm}$. Images were recorded using a $1 \mathrm{Kx} 1 \mathrm{~K}$ Slow Scan CCD camera. The statistical studies on particle size were carried out over 500 particles for each composition. The powders were characterized after impedance spectroscopy measurements by XRD and TEM. 


\subsection{Thermal analysis}

Differential thermal analysis (DTA) and thermogravimetric measurements (TG) were performed using a SETARAM TG-DTA 92 thermal analyzer. The experiments were carried out under static air up to $1200 \mathrm{~K}$ at a heating rate of $10 \% \mathrm{~min}$.

\subsection{Electric impedance spectroscopy}

The powders were compacted under a pressure of $140 \mathrm{MPa}$ during $5 \mathrm{~min}$, without any further sintering, and sandwiched between platinum electrodes. The porosity of the pellets was characterized by $P=1-\frac{\rho_{\exp }}{\rho_{\text {theo }}}$, with $\rho_{\exp }$ and $\rho_{\text {theo }}$ being the experimental and the theoretical densities of the pellets. Whatever the powders, the porosity was found to vary from 0.43 to 0.47. These porosity values are quite common for ferrites pellets $[19,29]$. The weak increase in porosity is linked to the small decreases in particles size [7]. Conductivity measurements were performed under air, using a Solarton SI 1260 AC impedance analyzer working in the frequency range from $10^{-1}$ to $10^{7} \mathrm{~Hz}$. Data were analyzed using a non linear least squares (NLLS) fitting routine. Several heating and cooling cycles were performed from room temperature to $600{ }^{\circ} \mathrm{C}$ in order to check the reproducibility of the measurements, followed by a final heating up to $900^{\circ} \mathrm{C}$.

\subsection{Magnetic measurements}

The magnetic measurements, in the temperature range between 4 and $300 \mathrm{~K}$, were performed using a Physical Property Measurement System (PPMS) from Quantum Design. The specified resolutions are $210^{-5} \mathrm{emu}$ in DC fields and $10^{-8} \mathrm{emu}$ for AC magnetization. The collected data were corrected from the diamagnetic contribution and presented in CGS units. The samples 
were compacted in a plastic sampling tube in order to minimize dipolar inter-particles interaction and to keep the particles from rotating rigid-body like as the applied field changes direction. The zero-field cooling (ZFC) curves were obtained by cooling to $20 \mathrm{~K}$ the sample under zero applied field, then applying a field of 100 Oe and slowly warming the sample to around $300 \mathrm{~K}$. The field cooling (FC) curves were obtained by cooling the sample from $300 \mathrm{~K}$ to $20 \mathrm{~K}$ under the same applied field.

3. Results and discussion

3.1 Structure and morphology of the cobalt ferrite $\mathrm{Co}_{\mathrm{x}} \mathrm{Fe}_{3-\mathrm{x}} \mathrm{O}_{4}$ nanoparticles

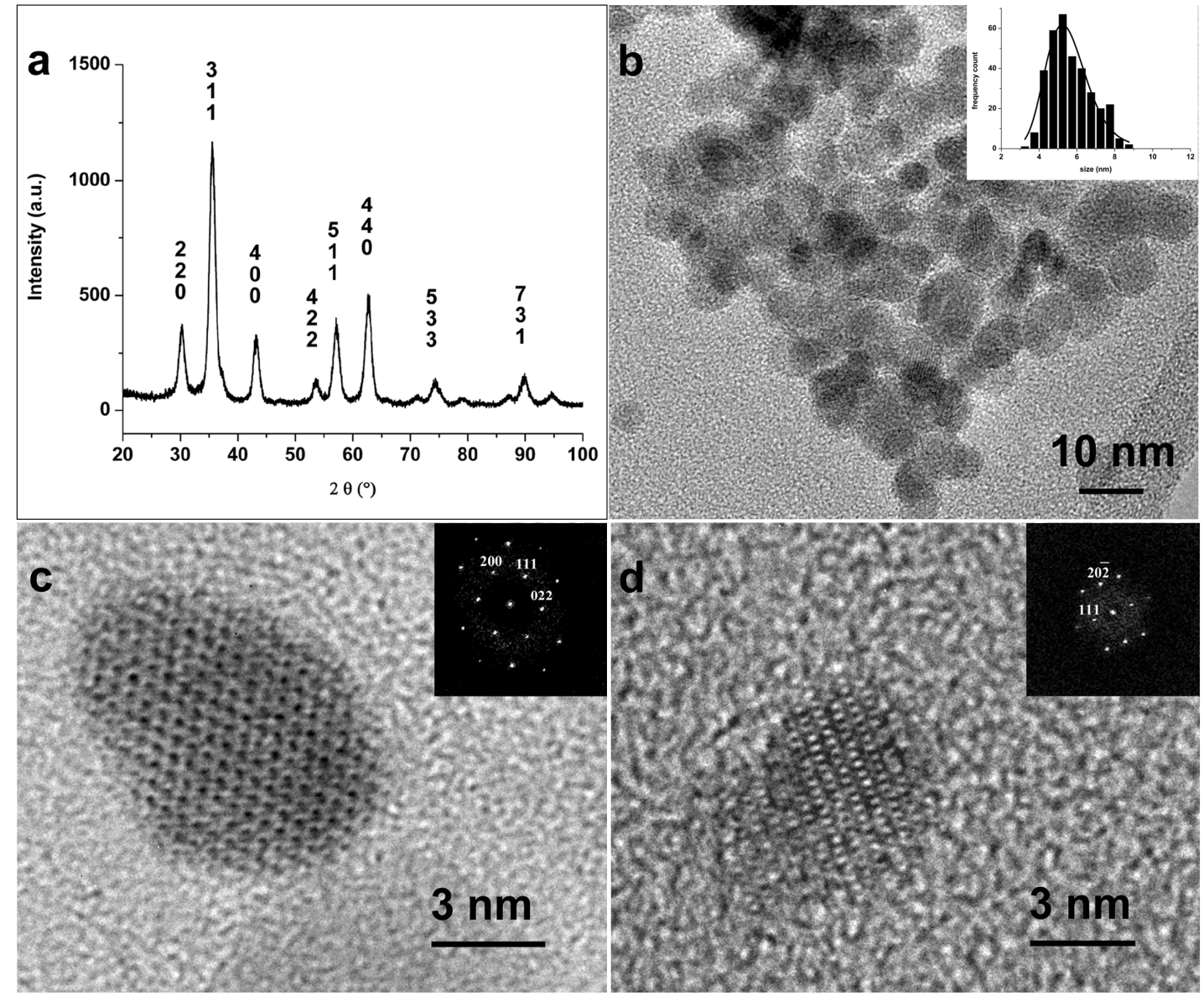

Figure 1: a) X rays diagram of the $\mathrm{Co}_{1.2} \mathrm{Fe}_{1.8} \mathrm{O}_{4}$ nanopowder, indexed in the spinel structure, b) TEM image of $\mathrm{Co}_{1.2} \mathrm{Fe}_{1.8} \mathrm{O}_{4}$ nanoparticles, along with the size distribution.c) and d) HRTEM images of single cobalt ferrites

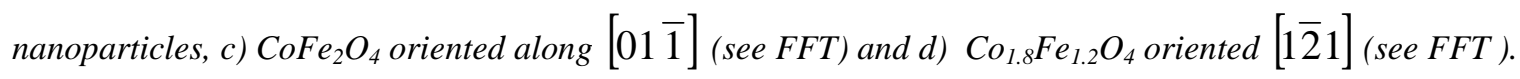


For the different compositions, the cobalt ferrites powders are single phased and have the expected spinel structure (space group Fd-3m). Fig1.a shows the XRD diagram corresponding to $\mathrm{Co}_{1.2} \mathrm{Fe}_{1.8} \mathrm{O}_{4}$. Fig.1b shows typical cobalt ferrite nanoparticles obtained for $\mathrm{x}=1.2$, along with the size distribution. The log normal function fitted very well the distribution size of the particles and led to somewhat smaller values that those obtained using the gaussian function [7]. The mean sizes and the associated standard deviation deduced from the log normal fits are given in Table 1. For $\mathrm{x}=0.6,1$ and 1.2, the particles have an almost spherical and regular shape (see Fig.1c for $\mathrm{x}=1$ ). The mean size of the nanoparticles decreases slightly with increasing cobalt amount $\mathrm{x}$ in $\mathrm{Co}_{\mathrm{x}} \mathrm{Fe}_{3-\mathrm{x}} \mathrm{O}_{4}$ and the smallest one is obtained for the highest quantity of cobalt $(\mathrm{x}=1.8, \mathrm{D}=4.3 \mathrm{~nm})$. For this latter composition, the shape of the particles is no more spherical (see Fig.1d) and not well defined. HRTEM study performed on all the nanopowders shows that the produced particles exhibit high crystallinity with no significant number of defects such as dislocations or stacking faults (Fig.1c and 1d).

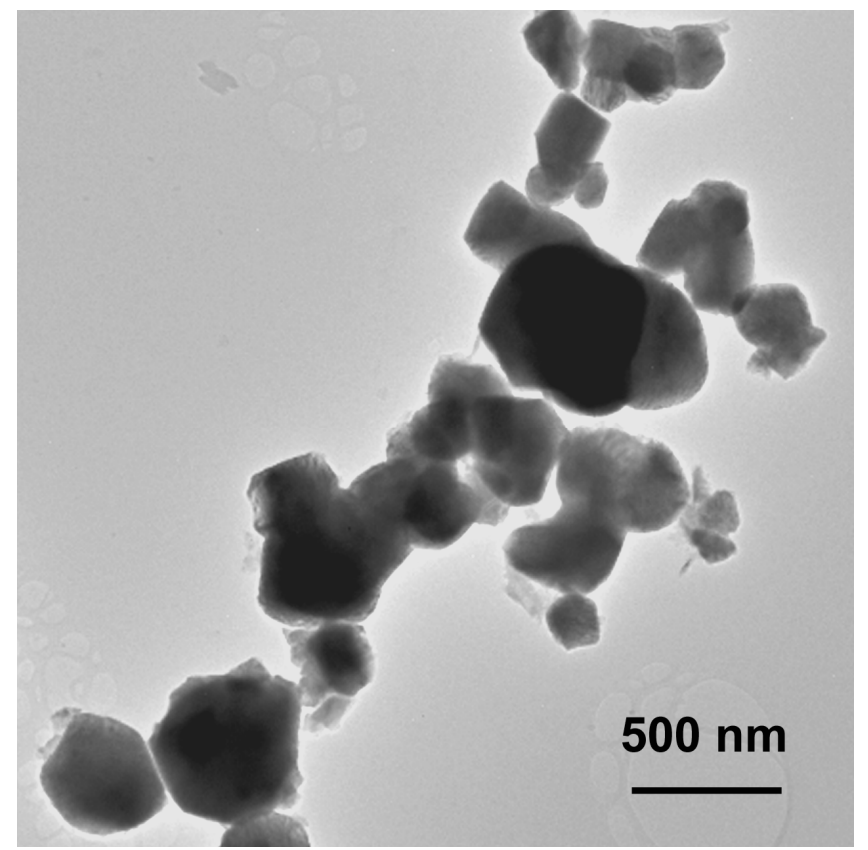

The $\mathrm{Co}_{\mathrm{x}} \mathrm{Fe}_{3-\mathrm{x}} \mathrm{O}_{4}$ pellets used for impedance spectroscopy were characterized by XRD and TEM coupled to EDS. During the electrical impedance spectroscopy measurements, these pellets were heated up to $900^{\circ} \mathrm{C}$, thus were liable to possible phase transitions and grain growth. Fig.2 shows typical grains of the pellets heated up to $900{ }^{\circ} \mathrm{C}$.

Figure 2: TEM image showing submicronic grains, from a pellet of $\mathrm{Co}_{1.8} \mathrm{Fe}_{1.2} \mathrm{O}_{4}$ heated up to $900^{\circ} \mathrm{C}$. 
For all the compositions, the grain sizes are submicronic, ranging between 200 and $600 \mathrm{~nm}$, although it remains some smaller grains (Fig.2). This shows that significant grain growth occurred during impedance spectroscopy measurements. For $\mathrm{CoFe}_{2} \mathrm{O}_{4}$ and $\mathrm{Co}_{1.2} \mathrm{Fe}_{1.8} \mathrm{O}_{4}$ the chemical composition remains the same upon heating and the

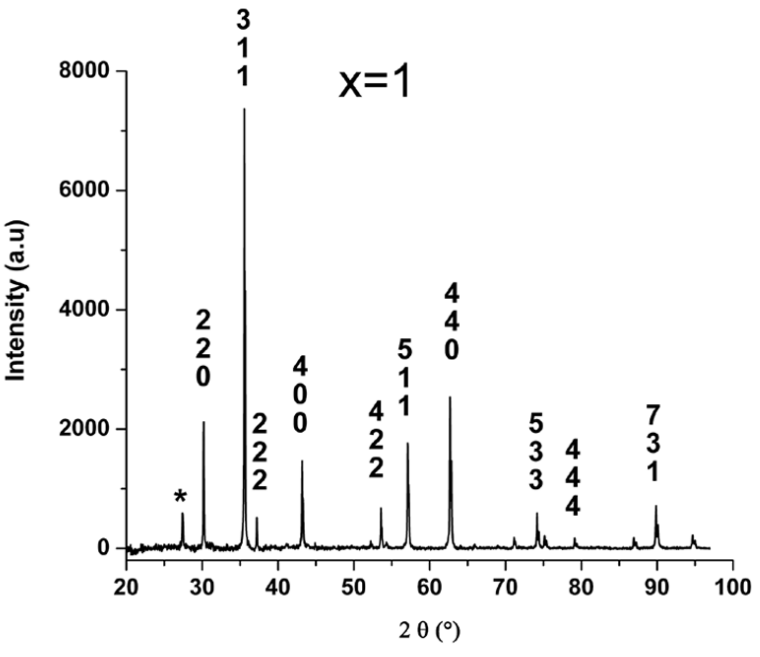
XRD diagram matches well with one single cubic spinel phase (see Fig.3a). For $\mathrm{x}=0.6$ and $\mathrm{x}=1.8, \mathrm{EDS}$ analysis showed composition fluctuations. For $\mathrm{x}=0.6$, the annealed pellet consists in a mixture of pure iron oxide grains and grains with atomic composition of $33 \% \mathrm{Co}, 67 \% \mathrm{Fe}$,

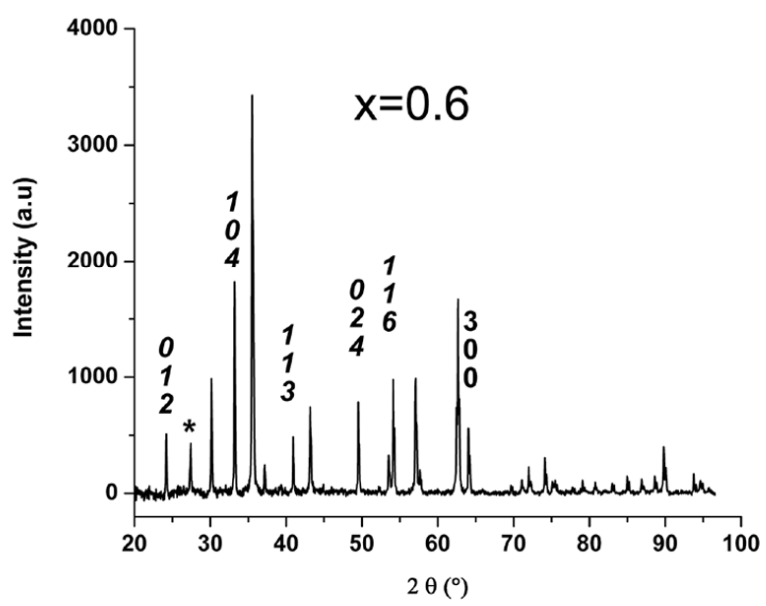
which corresponds to the $\mathrm{CoFe}_{2} \mathrm{O}_{4}$ stoichiometric composition. The corresponding XRD diagram (Fig.3b) could be refined with two phases, the $\mathrm{CoFe}_{2} \mathrm{O}_{4}$ spinel phase and $\alpha-\mathrm{Fe}_{2} \mathrm{O}_{3}$.

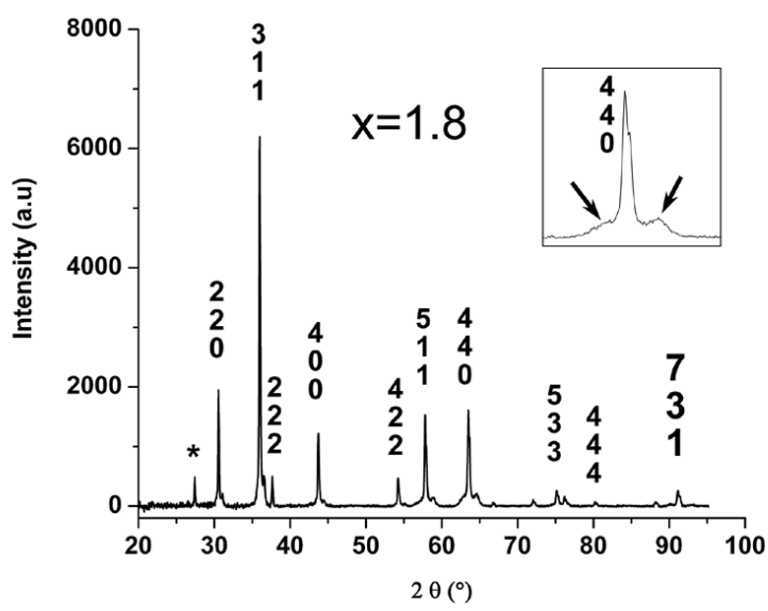

Figure 3: X-rays diagrams corresponding to pellets of cobalt ferrite heated up to $900^{\circ} \mathrm{C}$. * denotes a peak due to the sample holder. a) $\mathrm{CoFe}_{2} \mathrm{O}_{4}$ nanopowder, b) $\mathrm{Co}_{0.6} \mathrm{Fe}_{2.4} \mathrm{O}_{4}$ nanopowder, c) $\mathrm{Co}_{1.8} \mathrm{Fe}_{1.2} \mathrm{O}_{4}$ nanopowder. The diffraction peaks were indexed in the spinel structure for samples $x=1$ and $x=1.8$. For sample $x=0.6$, only the diffractions peaks corresponding to $\alpha-\mathrm{Fe}_{2} \mathrm{O}_{3}$ were indexed. 
For $\mathrm{x}=1.8$, the pellet consists mainly of grains with the atomic composition $60 \%$ Co and $40 \%$ $\mathrm{Fe}$, namely the nominal composition, but grains with less cobalt $(x=1)$ and grains with more cobalt $(\mathrm{x}=2.3)$. Rietveld refinement of the corresponding $\mathrm{X}$ rays diagram matches well with the EDS composition results of one major spinel phase, and two minor spinel phases with different cell parameters (Fig.3c). The zoom of the (440) peak in Fig.3c evidences one small peak on the high angle side and a bump on the low-angle side, corresponding respectively to the spinel phase with $\mathrm{x}=2.3$ and to the spinel phase with $\mathrm{x}=1$. As for $\mathrm{x}=1.8$, only part of the cobalt ferrite undergoes a transition into two spinel phases, one rich in cobalt and the other one poor in cobalt. This is consistent with the occurrence of a spinodal decomposition with slow kinetic observed for $\mathrm{Co}_{2} \mathrm{FeO}_{4}[30-31]$.

\subsection{Cation distribution}

The physical properties of cobalt ferrite spinel are linked to the cation distribution over the tetrahedral sites A (8a) and octahedral sites B (16d) of the structure. In bulk spinel, cations have usually a preference for a particular site. In cobalt ferrite with only $\mathrm{Co}^{2+}$, cobalt ions show a strong preference for octahedral sites [32]. In case of cobalt ferrite with two valence states for cobalt, $\mathrm{Co}^{3+}$ cations occupy exclusively octahedral sites and $\mathrm{Co}^{2+}$ cations are on tetrahedral sites. Recently, Kumar et al [33] showed that in case of nanocrystalline materials, this does not hold anymore. One way to obtain information about cation distribution is to consider the relative intensity of the (220), (222) and (422) diffraction peaks in X-rays diagrams. For Miller indices (hkl) all even with $h+k+l=4 n$, like (220) and (422), only the tetrahedral sites (8a) contribute to the diffraction peaks, as for Miller indices all even with $\mathrm{h}$, $\mathrm{k}, 1=4 \mathrm{n}$ or $\mathrm{h}, \mathrm{k}, \mathrm{l}=4 \mathrm{n}+2$, like (222), only the octahedral sites (16d) contribute to the diffraction peaks. Thus the ratio $\mathrm{I}_{220} / \mathrm{I}_{222}, \mathrm{I}_{422} / \mathrm{I}_{222}$ are an indication of the $\mathrm{A}$ and $\mathrm{B}$ sites occupation. Using Origin software, a whole peak fitting with pseudo Voigt functions was performed, and the intensity for each peak was extracted. The experimental relative intensities 
$\mathrm{I}_{220} / \mathrm{I}_{222}$ and $\mathrm{I}_{422} / \mathrm{I}_{222}$ are reported in Table 2 as a function of $\mathrm{x}$, the cobalt content. Clearly, the ration $\mathrm{I}_{220} / \mathrm{I}_{222}$ is more sensitive to the cobalt content than the $\mathrm{I}_{422} / \mathrm{I}_{222}$ ratio. Theoretical powder $\mathrm{X}$ rays diagrams were calculated, with the CaRIne software [34] for various cation distributions on A and B sites and $\mathrm{I}_{220} / \mathrm{I}_{222}, \mathrm{I}_{422} / \mathrm{I}_{222}$ ratios were calculated (see Table 2).

\begin{tabular}{|c|c|c|c|c|c|}
\hline $\mathrm{x}$ & Cation distribution & $\begin{array}{c}\mathrm{I}_{220} / \mathrm{I}_{222} \\
\mathrm{cal}\end{array}$ & $\begin{array}{c}\mathrm{I}_{220} / \mathrm{I}_{222} \\
\exp \end{array}$ & $\begin{array}{c}\mathrm{I}_{422} / \mathrm{I}_{222} \\
\text { cal }\end{array}$ & $\begin{array}{c}\mathrm{I}_{422} / \mathrm{I}_{2222} \\
\exp \end{array}$ \\
\hline $0\left(\gamma-\mathrm{Fe}_{2} \mathrm{O}_{3}\right)$ & {$\left[\mathrm{Fe}^{3+}\right]_{A}\left[\mathrm{Fe}_{0.831}^{3+} \otimes_{0.169}\right]_{B} O_{4}$} & 9.3 & & 3.1 & \\
\hline $0\left(\mathrm{Fe}_{3} \mathrm{O}_{4}\right)$ & {$\left[F e^{3+}\right]_{A}\left[F e_{0.5}^{3+} F e_{0.5}^{2+}\right]_{B} O_{4}$} & 3.4 & & 1.1 & \\
\hline \multirow[t]{3}{*}{0.6} & {$\left[\mathrm{Co}_{0.6}^{2+} \mathrm{Fe}_{0.4}^{3+}\right]_{A}\left[\mathrm{Fe}_{0.935}^{3+} \otimes_{0.065}\right]_{B} \mathrm{O}_{4}$} & 4 & 5.8 & 1.3 & 1.8 \\
\hline & $0.6\left[\mathrm{Co}^{2+}\right]_{A}\left[\mathrm{Fe}^{3+}\right]_{B} \mathrm{O}_{4}+0.4$ & 6 & & 2 & \\
\hline & {$\left[F e^{3+}\right]_{A}\left[F e_{0.831}^{3+} \otimes_{0.169}\right]_{B} O_{4}$} & & & & \\
\hline \multirow[t]{2}{*}{1} & {$\left[\mathrm{Fe}^{3+}\right]_{A}\left[\mathrm{Co}_{0.5}^{2+} \mathrm{Fe}_{0.5}^{3+}\right]_{B} \mathrm{O}_{4}$} & 3 & 4.4 & 1 & 1.7 \\
\hline & {$\left[\mathrm{Co}^{2+}\right]_{A}\left[\mathrm{Fe}^{3+}\right]_{B} \mathrm{O}_{4}$} & 4.1 & & 1.3 & \\
\hline \multirow[t]{3}{*}{1.2} & {$\left[\mathrm{Co}^{2+}\right]_{A}\left[\mathrm{Fe}_{0.9}^{3+} \mathrm{Co}_{0.1}^{2+}\right]_{B} \mathrm{O}_{4-0.1}$} & 3.9 & 6.4 & 1.3 & 1.2 \\
\hline & {$\left[\mathrm{Co}^{2+}\right]_{A}\left[\mathrm{Fe}_{0.9}^{3+} \mathrm{Co}_{0.1}^{3+}\right]_{B} \mathrm{O}_{4}$} & 4 & & 1.3 & \\
\hline & {$\left[\mathrm{Co}^{2+}\right]_{A}\left[\mathrm{Fe}_{0.82}^{3+} \mathrm{Co}_{0.05}^{2+} \otimes_{0.13}\right]_{B} O_{4-0.1}$} & 5.8 & & 1.9 & \\
\hline \multirow[t]{2}{*}{1.8} & {$\left[\mathrm{Co}^{2+}\right]_{A}\left[\mathrm{Fe}_{0.6}^{3+} \mathrm{Co}_{0.4}^{2+}\right]_{B} \mathrm{O}_{4-0.4}$} & 3 & 2.9 & 1 & 0.9 \\
\hline & {$\left[\mathrm{Co}^{2+}\right]_{A}\left[\mathrm{Fe}_{0.6}^{3+} \mathrm{Co}_{0.4}^{3+}\right]_{B} \mathrm{O}_{4}$} & 4.2 & & 1.4 & \\
\hline
\end{tabular}

Table 2: X rays diffraction intensity ratio for different $\mathrm{Co}_{x} \mathrm{Fe}_{3-x} \mathrm{O}_{4}$ powders. Experimental (exp) intensity ration and for different cation distributions calculated ones (cal).

Different $\mathrm{Fe}^{3+}, \mathrm{Co}^{2+}, \mathrm{Co}^{3+}$ distributions on $\mathrm{A}$ and $\mathrm{B}$ sites were tested, with the constraint of global charge neutrality, which led in some cases to the occurrence of oxygen vacancies. For $\mathrm{x}=1$ and $\mathrm{x}=1.8$ comparison between experimental and calculated intensity ratios indicates clearly that in the nanopowders, $\mathrm{Co}^{2+}$ has a strong preference for tetrahedral sites, contrary to what occurs in bulk ferrites. This modification of cation distribution from bulk to nanoparticles was previously observed for $\mathrm{CoFe}_{2} \mathrm{O}_{4}$ [20]. For $\mathrm{x}>1$, the nanopowders contains 
only low amount of $\mathrm{Co}^{3+}$. The cobalt ferrites $\mathrm{x}=1.2$ and $\mathrm{x}=0.6$ exhibit high $\mathrm{I}_{220} / \mathrm{I}_{222}$ intensity ratios compared to those of $\mathrm{x}=1$ and $\mathrm{x}=1.8$, that could be reproduced by introducing vacancies on the octahedral sites of the spinel for $\mathrm{x}=1.2$, building a so called lacunar spinel . For $\mathrm{x}=0.6$, only a mixture of $60 \% \mathrm{CoFe}_{2} \mathrm{O}_{4}$ and $40 \%$ maghemite $\left(\gamma-\mathrm{Fe}_{2} \mathrm{O}_{3}\right)$ explained the high intensity ratio, which indicate that it was not possible to synthesise a single spinel phase with $\mathrm{x}=0.6$ using the solvo-thermal method developed. The lower limit of stability for $\mathrm{Co}_{\mathrm{x}} \mathrm{Fe}_{3-\mathrm{x}} \mathrm{O}_{4}$ spinel was found to be $\mathrm{x}=0.45$ in [22]. The cation distribution for the powders with $\mathrm{x}=1$ and $\mathrm{x}=0.6$ did not change significantly upon heating up to $900^{\circ} \mathrm{C}$. The X-rays intensity ratio $\mathrm{I}_{220} / \mathrm{I}_{222}$ was found to be 3.9 for the sample corresponding to $\mathrm{x}=1.8$ after heating. This is consistent with an oxidation process with the disappearance of the oxygen vacancies, and the occurrence of $\mathrm{Co}^{+}$.

\subsection{Thermal stability}

The thermal stability of the cobalt ferrite phases was investigated by TG-DTA, from room temperature to $900{ }^{\circ} \mathrm{C}$. Fig 4 shows the relative weight variations associated to the enthalpy variations during the heating of the nanopowders under air. For all the samples, there is no weight gain observed, thus no oxidation process occurs under air for the various nanopowders. For the different compositions, one observe a first weight loss of 2-5\%, associated to an endothermic peak, related to water loss, which occurs in two steps, dehydratation and then loss of adsorbed water [35]. This water loss lasts until $270-300^{\circ} \mathrm{C}$. A second weight loss, which varies, depending on the samples, between $5 \%$ and $10 \%$, is associated to a high exothermic peak, and corresponds to the decarbonation of the nanopowders [35-36]. The decarbonation occurs between $300^{\circ} \mathrm{C}$ and $420^{\circ} \mathrm{C}$, but for $\mathrm{x}=0.6$, it lasts even until $500^{\circ} \mathrm{C}$ (Fig.4a). This indicates that it remains organic residuals in the 
nanopowders, coming from the precursor or the solvent, even after thoroughly washing [7].
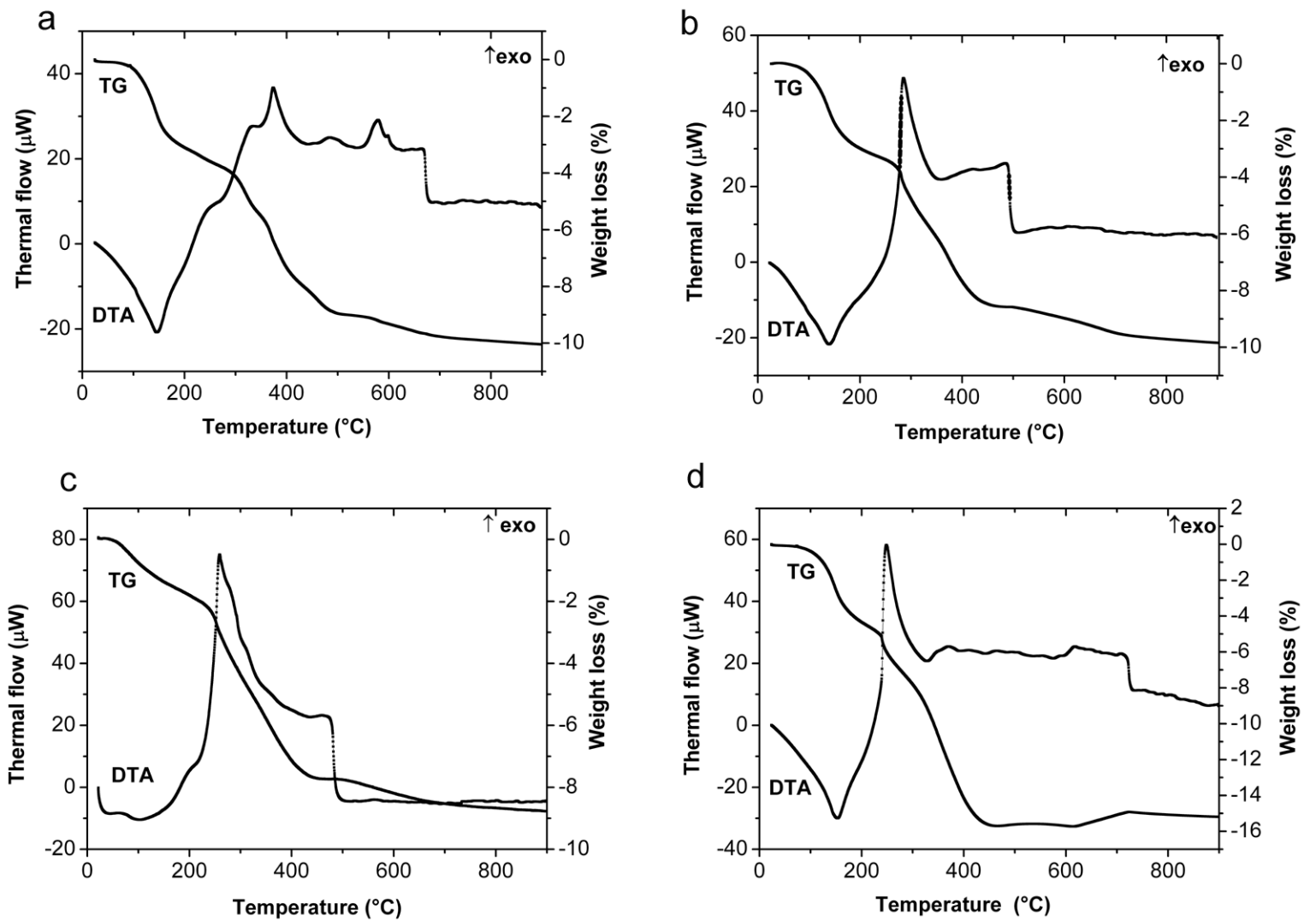

Figure 4: DTA-TG curves for different cobalt ferrite nanopowders: a) $\mathrm{Co}_{0.6} \mathrm{Fe}_{2.4} \mathrm{O}_{4}$ b) $\mathrm{CoFe}_{2} \mathrm{O}_{4}$ c) $\mathrm{Co}_{1.2} \mathrm{Fe}_{1.8} \mathrm{O}_{4}$ d) $\mathrm{Co}_{1.8} \mathrm{Fe}_{1.2} \mathrm{O}_{4}$.

At higher temperatures, there is nearly no weight loss (less than $1 \%$ ), but changes in the DTA curve occured indicating phase and magnetic transitions. For the powders with $x=1$ and $x=1.2$ (Fig.4b, Fig.4c) only one endothermic event occurs, at $480-490^{\circ}$, characteristic of a second order transition [37], which corresponds to a magnetic transition at Curie temperature. The Curie temperature for bulk $\mathrm{CoFe}_{2} \mathrm{O}_{4}(\mathrm{x}=1)$, is $520^{\circ} \mathrm{C}$ [1], and the Curie temperature in nanoparticles can be reasonably assumed to be lower than the bulk value. For $\mathrm{x}=0.6$ and $\mathrm{x}=1.8$ (Fig.4a, Fig.4d) the DTA curves are much more complex but can be interpreted knowing that phase transitions occur at high temperatures (see 3.1). The cobalt ferrite with $\mathrm{x}=0.6$ is not stable and undergoes a phase transition, revealed by the exothermic peak from 550 to $625^{\circ} \mathrm{C}$. The kink in the DTA curve at $660^{\circ} \mathrm{C}$ is characteristic for a second order phase transition and 
corresponds to the ferro-para transition of $\alpha-\mathrm{Fe}_{2} \mathrm{O}_{3}$ [38]. Thus, cobalt ferrite with $\mathrm{x}=0.6$ is transformed into hematite and $\mathrm{CoFe}_{2} \mathrm{O}_{4}$. This interpretation is supported by the $\mathrm{X}$ ray intensity ratio in Table 2, which shows that the compound $\mathrm{x}=0.6$, at ambient, corresponds to a mixture of $\mathrm{CoFe}_{2} \mathrm{O}_{4}$ and maghemite $\gamma-\mathrm{Fe}_{2} \mathrm{O}_{3}$. For $\mathrm{x}=1.8$ (Fig.4d), one observes a large exothermic plateau which can be related to the partial decomposition of the cobalt ferrite nanograins with $\mathrm{x}=1.8$ into two spinel phases. No magnetic transitions are observed in the DTA curve of $\mathrm{x}=1.8$ because the spinel phases have Curie temperatures lower than $500^{\circ} \mathrm{C}$ [39].

\subsection{Conductivity}

Depending on temperature, two types of Nyquist diagrams were obtained, a single depressed semicircle, or a straight line parallel to the imaginary axis. The single depressed semicircle was modelled by a resistance in parallel with a constant phase element (CPE) [40], and the straight line by a resistance in series with the inductance of the wires. For the nano ferrites powders, due to their small size, the intergrain conduction is the predominant phenomenon and only one low frequency semi circle was observed. At high temperature, due to apparatus limitation at high frequencies, the contribution of the wires to the imaginary part of the impedance became preponderant.

Cobalt ferrites are known to be semi conducting material, and this is confirmed by the increasing of conductivity with temperature for the four tested compositions (Fig.5). From room temperature up to a limit temperature $T_{1}$, depending on composition, one observes an Arrhenius law dependence of the conductivity, and the corresponding activation energies $\left(\mathrm{E}_{\mathrm{a}}\right)$ are reported in Table 3, along with the $T_{1}$ values. At higher temperatures than $T_{2}$, one observes also Arrhenius dependence of the conductivity, but with a much weaker slope, depending on the composition of the powders, and the corresponding activation energies are reported in Table 3 , along with the $\mathrm{T}_{2}$ values. The conductivity values at two different 


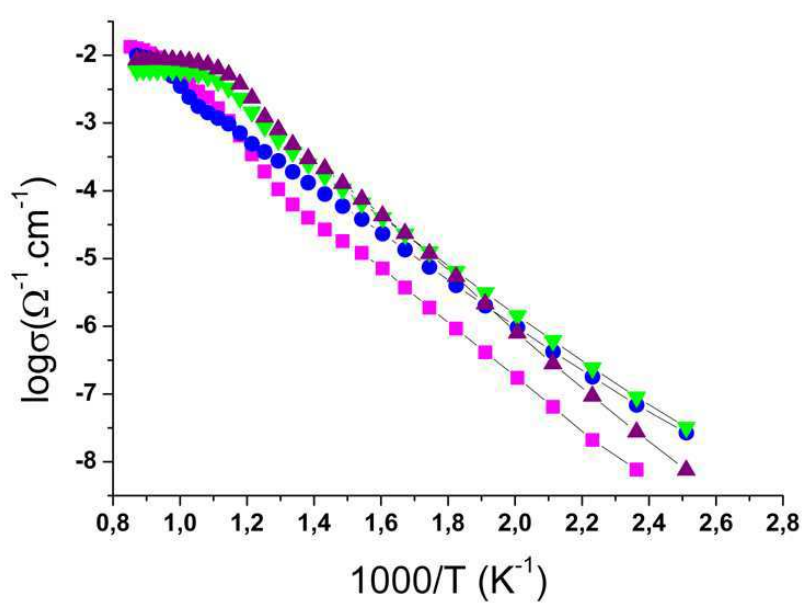

temperatures $\left(\mathrm{T}<\mathrm{T}_{1}\right.$ and $\left.\mathrm{T}>\mathrm{T}_{2}\right)$ are reported in Table 3. For $\mathrm{T}<\mathrm{T}_{1}, \mathrm{Ea}$ values are about $0.7 \mathrm{eV}$ for $\mathrm{x}=1$ and $\mathrm{x}=1.2$, and about $0.8 \mathrm{eV}$, for $\mathrm{x}=0.6$ and 1.8, thus higher activation energy values for off-stoichiometry compounds. At low temperatures, typically $200^{\circ} \mathrm{C}$, the

Figure 5: Conductivity versus temperatures for $\mathrm{Co}_{x} \mathrm{Fe}_{3-x} \mathrm{O}_{4}$ powders , $x=0.6(\square), x=1(O) x=1.2(\nabla)$ and $x=1.8(\Delta)$.

compounds with $\mathrm{x}=1, \mathrm{x}=1.2$ and 1.8 have similar conductivity values, in the $10^{-7} \Omega^{-1} . \mathrm{cm}^{-1}$ range, and $x=0.6$ has a lower conductivity value in the $10^{-8} \Omega^{-1} \cdot \mathrm{cm}^{-1}$ range.

\begin{tabular}{lllll}
\hline $\mathrm{x}$ & $\mathbf{0 . 6}$ & 1 & 1.2 & 1.8 \\
\hline Ea $(\mathrm{eV}) \mathrm{T}<\mathrm{T}_{1}$ & 0.77 & 0.67 & 0.70 & 0.84 \\
$\mathrm{~T}_{1}\left({ }^{\circ} \mathrm{C}\right)$ & 500 & 625 & 525 & 525 \\
Ea $(\mathrm{eV}) \mathrm{T}>\mathrm{T}_{2}$ & 0.23 & 0.24 & 0.02 & 0.03 \\
$\mathrm{~T}_{2}\left({ }^{\circ} \mathrm{C}\right)$ & 725 & 825 & 625 & 625 \\
$\sigma\left(\Omega^{-1} \cdot \mathrm{cm}^{-1}\right)$ at $200^{\circ} \mathrm{C}$ & $6.410^{-8}$ & $4.210^{-7}$ & $6.110^{-7}$ & $2.810^{-7}$ \\
$\sigma\left(\Omega^{-1} \cdot \mathrm{cm}^{-1}\right)$ at $900^{\circ} \mathrm{C}$ & $3.710^{-2}$ & $2.410^{-2}$ & $1.010^{-2}$ & $1.610^{-2}$
\end{tabular}

Table 3 : Activation energies for two different temperature ranges and AC conductivity at low $\left(200^{\circ} \mathrm{C}\right)$ and high $\left(900^{\circ} \mathrm{C}\right)$ temperatures, for different $\mathrm{Co}_{x} \mathrm{Fe}_{3-\mathrm{x}} \mathrm{O}_{4}$ nanopowders,

At high temperature $\left(T>T_{2}\right)$, the conductivity values of the different compounds are similar, in the $10^{-2} \Omega^{-1} \cdot \mathrm{cm}^{-1}$ range (see Table 3 ), and for compounds with high cobalt amount $(\mathrm{x}=1.2$ and $\mathrm{x}=1.8$ ), the conductivity does not vary with temperature, as evidenced in Fig.5. The activation energies are correspondingly very weak (see Table 3). 
Conduction in ferrites occurs by polaron hopping between pairs of cations situated on octahedral sites of the spinel structure [41-42]. In fact, distances between two nearest octahedral sites are smaller than distances between tetrahedral sites or distances between octahedral and tetrahedral sites. Charge carrier in cobalt ferrites can be $\mathrm{Co}^{2+}, \mathrm{Co}^{3+}, \mathrm{Fe}^{2+}, \mathrm{Fe}^{3+}$ and may all occupied octahedral sites. Historically, the Verwey rules stated that pairs of charge carrier can only be built by cations of the same element, with oxidation numbers differing by unity, situated on similar sites [43]. The higher mobility of electrons compared to holes leads to higher conductivity and lower activation energies for $\mathrm{Fe}^{2+} \leftrightarrow \mathrm{Fe}^{3+}$ pairs than for Co ${ }^{3+} \leftrightarrow \mathrm{Co}^{2+}$. Nowadays, it is established that pairs of charge carriers can be composed of cations of different elements, but the activation energies are higher in that case [20,44]. Intergrain conduction activation energies are dependant of the grain size of the powders, with very small size corresponding to high activation energies [20]. The high activation energies at low temperatures are consistent with the 4-7 nm grain sizes of the powder and with pairs of $\mathrm{Co}^{2+}$ and $\mathrm{Fe}^{3+}$ involved in the conduction process. The slightly higher activation energies for $\mathrm{x}=0.6$ and $\mathrm{x}=1.8$ can be related to defects that occur in non stoichiometric compounds. Significant grain growth occurred during the final heating, according to the structural XRD and TEM studies. Thus, the high temperature conductivity values correspond mainly to intragrain conduction. Consequently, for the different powders, the conductivity increased from a $10^{-7} \Omega^{-1} \cdot \mathrm{cm}^{-1}$ range to a $10^{-2} \Omega^{-1} \cdot \mathrm{cm}^{-1}$ range and the activation energy was lowered. The activation energies at high temperatures are consistent with intragrain conduction due to $\mathrm{Fe}$ ${ }^{2+} \leftrightarrow \mathrm{Fe}^{3+}$ pairs on octahedral sites [44], which could indicate a modification at high temperature of the cation distribution along with the grain growth. However, a comparison of the energy values is difficult because of the phase transitions that occurred for some compounds.

\subsection{Magnetic properties}



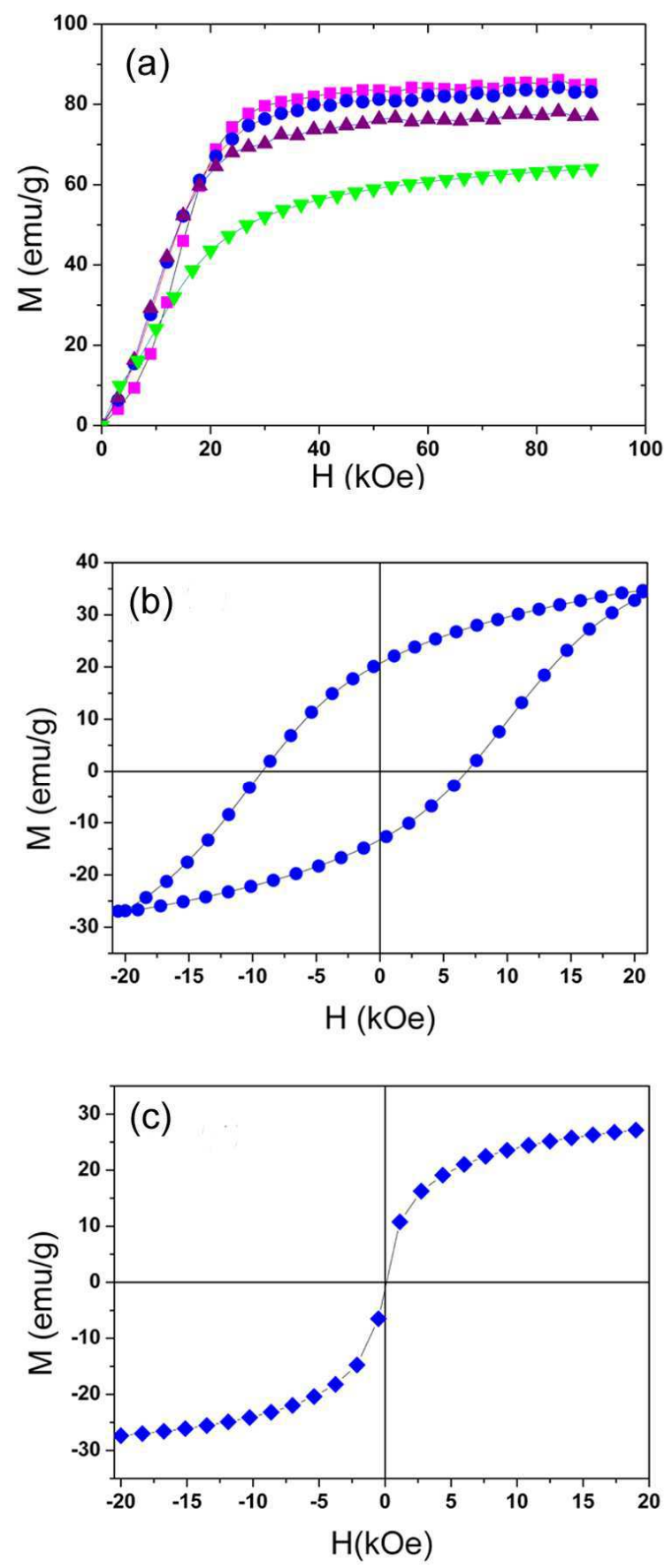

The $\mathrm{M}(\mathrm{H})$ magnetization curves (Fig6) were measured at $10 \mathrm{~K}$ with applied fields $\mathrm{H}$ up to 90 kOe. The saturation magnetization was deduced by fitting the high-field part of $\mathrm{M}(\mathrm{H})$ from 20 kOe using the saturation approach law $\mathrm{M}(\mathrm{H})$ $=\mathrm{MS}+\mathrm{a} / \mathrm{H} 2$, where $\mathrm{a}$ is a constant. The saturation magnetization values for the different nanopowders are reported in Table 4. The saturation magnetization Ms decreases with increasing cobalt content and with decreasing particles sizes. For $\mathrm{x}=1$ and $\mathrm{x}=0.6, \mathrm{Ms}$ values are close to those obtained for bulk cobalt ferrites (90emu/g at 10K) [45] as for powders with high cobalt content $(x=1.8)$, the Ms values are significantly lower than the bulk value. The latter composition corresponds to the smallest particle size $(4 \mathrm{~nm})$. It was already shown that Ms depends on particle size and on cobalt

Figure 6: a) Magnetization versus applied field at $10 \mathrm{~K}$

for $\mathrm{Co}_{x} \mathrm{Fe}_{3-x} \mathrm{O}_{4}$ powders $x=0.6(\square), x=1(O) x=1.2(\nabla)$

and $x=1.8(\Delta), b)$ and c) Magnetization curves for

$\mathrm{Co}_{1,8} \mathrm{Fe}_{1.2} \mathrm{O}_{4}$ under medium $\mathrm{H}$ field at two temperatures:

b) $10 \mathrm{~K}$, c) $300 \mathrm{~K}$.

content in the $x<1$ range $[46,22]$. In the composition range $1<x<2$, for particles with sizes around $30 \mathrm{~nm}$, Ms values lower than the bulk one were attributed to the existence of a 
structural "dead" surface layer, due to the formation of small nanoscale crystallite and residual strains during the sample synthesis [47].

\begin{tabular}{llll}
\hline $\mathrm{x}$ & $\mathrm{Ms}(\mathrm{emu} / \mathrm{g})$ & $\mathrm{T}_{\mathrm{B}}(\mathrm{K})$ & $\mathrm{K}\left(10^{6} \mathrm{erg} / \mathrm{cm}^{3}\right)$ \\
\hline 0.6 & 86 & 340 & 6.5 \\
1 & 84 & 300 & 7.2 \\
1.2 & 78 & 330 & 13 \\
1.8 & 63 & 200 & 21
\end{tabular}

Table 4: Saturation magnetization values at $10 \mathrm{~K}$, anisotropy constant and blocking temperatures for different

$$
\mathrm{Co}_{x} \mathrm{Fe}_{3-x} \mathrm{O}_{4} \text { nanopowders . }
$$

The high saturation magnetization values in this study (Table 4) suggest that the cobalt ferrite particles are almost perfectly magnetically ordered single-domains without a significant dead magnetic layer. The saturation magnetization values depend also on the synthesis method. For $\mathrm{CoFe}_{2} \mathrm{O}_{4}$ nanoparticles, $5 \mathrm{~nm}$ in size, at $5 \mathrm{~K}$, Ms values of $85 \mathrm{emu} / \mathrm{g}$ [48], $105 \mathrm{emu} / \mathrm{g} \mathrm{[45],} \mathrm{or}$ $94 \mathrm{emu} / \mathrm{g}$ [49] were found. The low value of Ms for $\mathrm{x}=1.8(66 \mathrm{emu} / \mathrm{g})$ are close to values found for very small cobalt ferrites nanoparticles [50]. Finally, the magnetic behaviour of the cobalt ferrite nanoparticles may vary with different $\mathrm{Fe}^{2+}$ and $\mathrm{Co}^{2+}$ site occupations, since the $\mathrm{Co}^{2+}$ ion is highly anisotropic [51]. According to the literature, the decrease in Ms in our study is mainly due to a size effect, the structural disorder at the surface of the particles being relatively more important for small particles. This structural disorder is accompanied by a magnetic disorder due to an alignment of spins relative to the direction of the overall magnetization of the particle, called "spin canting"[45]. Consequently, the magnetic environment will be frustrated compared to the bulk material, the more the spin disorder increases, the more the value of the magnetic moment decreases.

The isothermal hysteresis loop of the as-prepared $\mathrm{Co}_{1.8} \mathrm{Fe}_{1.2} \mathrm{O}_{4}$ nanoparticles carried out at temperature of $10 \mathrm{~K}$, with applied fields of up to $20 \mathrm{kOe}$, is presented in Fig.6b. An open hysteresis loop with a coercivity field ( $\mathrm{Hc})$ of about $8 \mathrm{kOe}$ can be clearly observed. Thus, the 
nanoparticles exhibit ferromagnetic behaviour with non-zero coercivity. This behaviour is characteristic of single domain cobalt ferrite nanoparticles. No hysteresis is observed at room temperature (Fig.6c) indicating that the $\mathrm{Co}_{1.8} \mathrm{Fe}_{1.2} \mathrm{O}_{4}$ particles exhibit superparamagnetic behaviour. The curve is completely reversible and can be described by the Langevin function. It is typical for superparamagnets which behave below their blocking temperature $\left(T_{B}\right)$ as ferromagnetics, but above $T_{B}$ show properties of classical paramagnets, with total spin equal to the spin of a whole particle. Similar results were observed for cobalt ferrite nanoparticles with sizes from 3 to $5 \mathrm{~nm}$ [49- 50, 52]. The squareness ratio $\mathrm{Mr} / \mathrm{Ms}$ at $10 \mathrm{~K}$ for $\mathrm{x}=1.8$ is 0.48 , thus near the expected value for uniaxial single-domain particles without interaction with a randomly oriented of the easy magnetic axis.

Fig. 7 shows the representative plots of zero-field cooled (ZFC) and field-cooled (FC) curves in a measuring field of 100 Oe for the different cobalt ferrites powders. Below the blocking temperature $\mathrm{T}_{\mathrm{B}}$, the $\mathrm{ZFC}$ and $\mathrm{FC}$ curves significantly diverge and the cobalt ferrite nanoparticles are in the ferromagnetic state. Above $\mathrm{T}_{\mathrm{B}}$, the ZFC and FC curves coincide, due to the fact that all nanoparticles are in the same superparamagnetic state. The sharp peak in the $\mathrm{ZFC}$ curve at $\mathrm{T}_{\mathrm{B}}$ is an evidence of a narrow energy barrier distribution. 

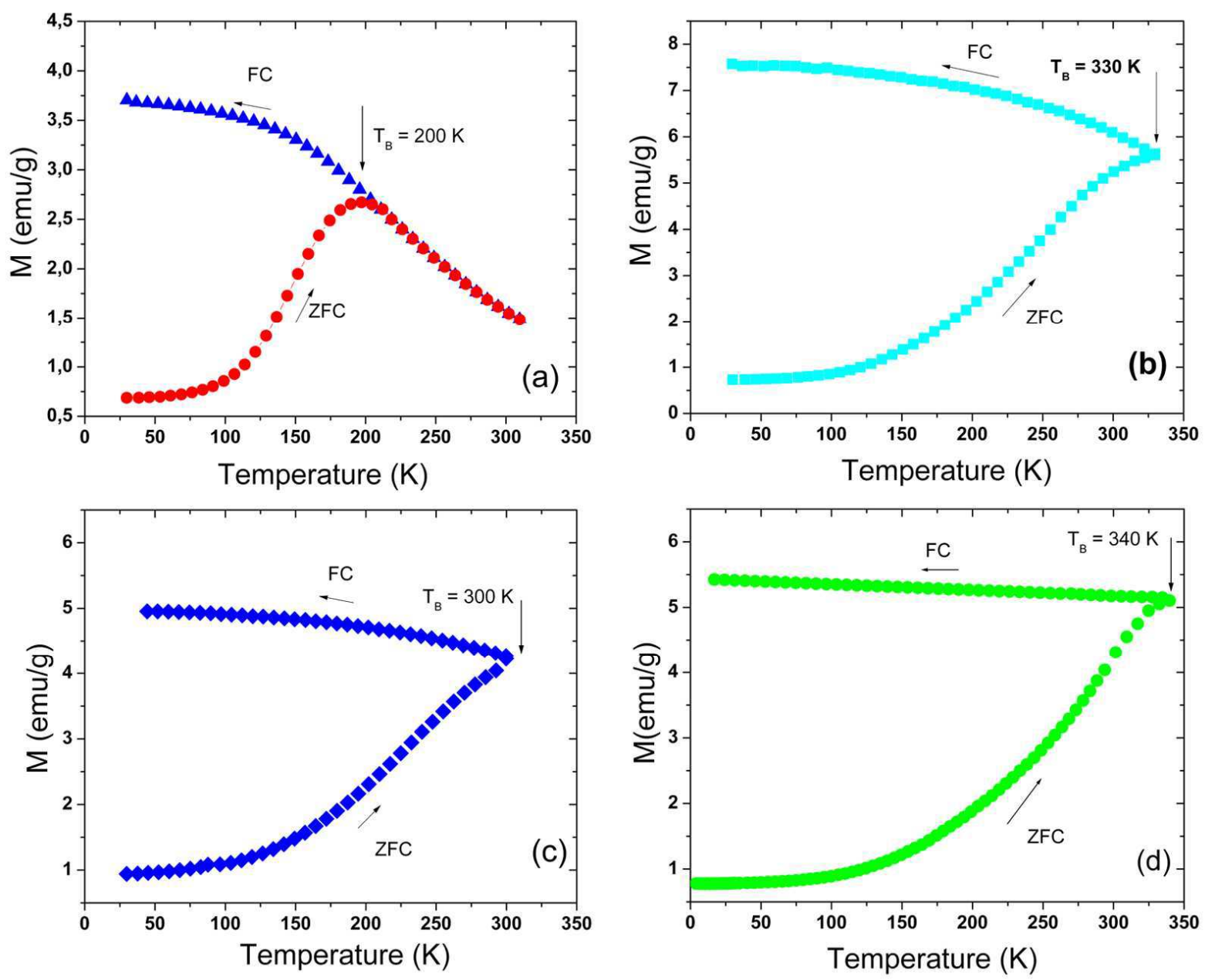

Figure 7: ZFC-FC magnetization curves versus temperature for $\mathrm{Co}_{x} \mathrm{Fe}_{3-x} \mathrm{O}_{4}$ powders under an applied field of 100 Oe. : a) $x=1.8, b) x=1.2$, c) $x=1$ and d) $x=0.6$.

It can be seen that the blocking temperature increases with decreasing cobalt amount (or increasing particle size). Moreover, with increasing particle size, the peak in the ZFC curve becomes broader which indicates the presence of a broad distribution of relaxation times for the metastable magnetic states. Except for the $\mathrm{Co}_{1.8} \mathrm{Fe}_{1.2} \mathrm{O}_{4}$ sample (Fig.7a), all samples present blocking temperatures higher than room temperature (Fig.7b,c,d). The smallest blocking temperature $T_{B}=200 \mathrm{~K}$ is observed for $\mathrm{x}=1.8$ which corresponds to an average size of $4 \mathrm{~nm}$. The same value of $T_{B}$ was observed for a nanopowder of $5 \mathrm{~nm}$ in size but for a composition of $x=1$ [45]. For bigger particle volumes, the anisotropy energy is increased, which causes a decrease of the jump probability across the anisotropy barrier. Hence the 
blocking phenomenon is shifted to a higher temperature [47, 53]. A blocking temperature value closed to $350 \mathrm{~K}$ was already obtained for ferrite powders with a cobalt content $\mathrm{x}=0.6$ [56].

Fig.7a (composition $\mathrm{x}=1.8$ ) shows that the ZFC magnetization exhibits a rather large maximum centred at a temperature $T_{\max }=197 \mathrm{~K}$. The FC magnetization increases and remains constant below $\cong 50 \mathrm{~K}$. The two curves split at a temperature $\left(T_{i r r}\right)$ above $T_{\max }$; the largest size of the unblocked particles can be related to the irreversibility temperature $T_{i r r}$ using the BeanLivingston equation [52] : $T_{i r r}=K V_{\max } / 25 k_{B}$, where $V_{\max }$ is the volume of the largest particle. The variation of $T_{B}$ is then related to the size of individual particles, the size distribution for each sample as well as their shape.

The blocking temperature of nanospinels is known to be influence by the spin-orbit interaction in constituent metal ions $\left(\mathrm{Co}^{2+}, \mathrm{Fe}^{3+}\right)$. For nanocrystallites with the same size, there can be a different occupation of the A (tetrahedral) and B (octahedral) sites by $\mathrm{Co}^{2+}$ and $\mathrm{Fe}^{3+}$, and cations in these two different site symmetries exhibit different spin-orbit couplings [55]. Several studies, mainly on $\mathrm{CoFe}_{2} \mathrm{O}_{4}$, have shown that $\mathrm{T}_{\mathrm{B}}$ also depends on the synthesis method $[33,45,48,55]$. For an assembly of $\mathrm{CoFe}_{2} \mathrm{O}_{4}$ nanoparticles with the same average size of $5 \mathrm{~nm}$, obtained by different synthesis method, blocking temperatures of $195 \mathrm{~K}$ [45] and $267 \mathrm{~K}[57]$ were found. The increase in $\mathrm{T}_{\mathrm{B}}$ was then linked to the increase of $\mathrm{Co}^{2+}$ ions in the octahedral sites. However, the cation distribution obtained from XDR diagram (see 3.1) indicates more $\mathrm{Co}^{2+}$ on octahedral sites for high cobalt content than for low cobalt content. Therefore, this effect is negligible with regards to the influence of the grain size in our compounds. Besides particle size, the blocking temperature can also be influenced by several intrinsic factors, which mainly include magnetocrystalline, surface and shape anisotropy and extrinsic factors, generally related to interactions between particles [48]. 


\subsection{Anisotropy}

The magnetocrystalline anisotropy constant $(K)$ of the nanoferrites was estimated from the measured $T_{B}$ for the isolated particles using the Neel-Brown relaxation law with an experimental time scale of $100 \mathrm{~s}: K=25 k_{B} T_{B} /<V>$ where $\mathrm{k}_{\mathrm{B}}$ is the Boltzman constant and $\langle V\rangle$ is the mean volume of a monodomain [58-59]. The obtained results are reported in Table 4. For all samples, the value of the anisotropy constant is higher than the bulk value (between 2.1 and $3.910^{6} \mathrm{erg} / \mathrm{cm}^{3}$ ), reaching $\mathrm{K}=2110^{6} \mathrm{erg} / \mathrm{cm}^{3}$ for $\mathrm{x}=1.8$. The estimated anisotropy constant values decrease as the particle size increases.

Larger particles have not only less surface area to interact, but the fraction of surface area in contact with others particles becomes smaller due to the less efficient packing [47]. This is

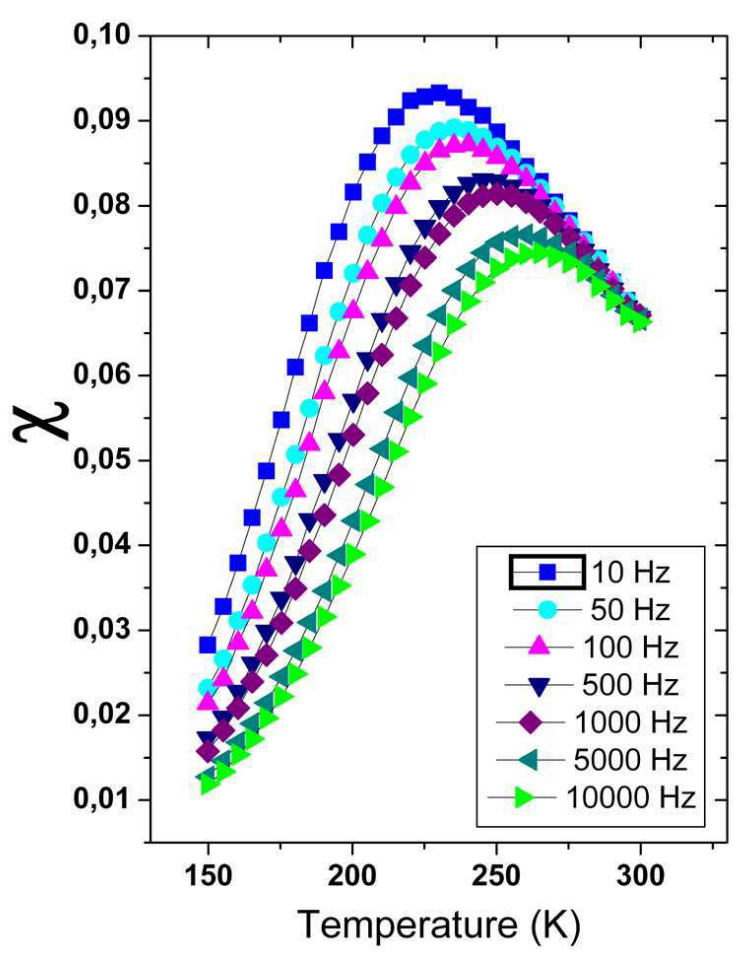
due to the surface anisotropy, the size and shape related effects $[2,60]$ and to the presence of $\mathrm{Co}^{2+}$ ions in the octahedral sites of the spinel structure [47]. In fact, in bulk materials, magnetocrystalline and magnetostatic energies are the main sources of anisotropy, whereas in fine particles and nanostructures other kinds of anisotropies such as shape, strain and surface anisotropy are relevant in addition.

Figure 8: Temperature dependence of the real part of the AC magnetic susceptibility for $\mathrm{Co}_{1.8} \mathrm{Fe}_{1.2} \mathrm{O}_{4}$ ferrite at different frequencies. 
For small particles, the surface anisotropy will be the dominant mechanism.

In the case of small spherical particles the magnetic anisotropy can be expressed as $\mathrm{K}=\mathrm{K}_{\mathrm{v}}+$ $\mathrm{S} / \mathrm{V} \mathrm{K}_{\mathrm{s}}$, where $\mathrm{K}_{\mathrm{s}}$ is the surface contribution and $\mathrm{K}_{\mathrm{v}}$ the volume anisotropy consisting of magnetocrystalline, magnetostriction and shape anisotropy, $\mathrm{S}$ and $\mathrm{V}$ are the surface and volume of the particle. $\mathrm{K}$ value as high as $30 \times 10^{6} \mathrm{erg} \mathrm{cm}^{-3}$ was obtained for very small particles of $\mathrm{Co}$, whose $\mathrm{K}$ bulk value is $2.7 \times 10^{6} \mathrm{erg} \mathrm{cm}^{-3}$ [61].

The in-phase components of the AC susceptibility versus temperature data provided a series of peaks that shift up with increasing frequency (Fig.8). These shifts fit the Neel-Brown model with small magnetite nanocrystals [62], in agreement with the $\mathrm{Co}_{\mathrm{x}} \mathrm{Fe}_{3-\mathrm{x}} \mathrm{O}_{4}$ particle sizes.

\section{Conclusion}

$\mathrm{Co}_{\mathrm{x}} \mathrm{Fe}_{3-\mathrm{x}} \mathrm{O}_{4}$ nanopowders, $4 \mathrm{~nm}$ to $8 \mathrm{~nm}$ in size, were synthesized using a one pot solvothermal route. Their electric and magnetic properties as well as their thermal stability were investigated. These properties were linked to the morphology, composition of the particles and to the cation distribution on octahedral and tetrahedral sites. Nanopowders with $\mathrm{x}=1$ and 1.2 are stable up to $900^{\circ} \mathrm{C}$. The $\mathrm{Co}_{1.8} \mathrm{Fe}_{1.2} \mathrm{O}_{4}$ nanopowder undergoes a partial phase transition around $600{ }^{\circ} \mathrm{C}$, leading to $\mathrm{CoFe}_{2} \mathrm{O}_{4}$ and $\mathrm{Co}_{2.3} \mathrm{Fe}_{0.7} \mathrm{O}_{4}$ spinel phases. The nanopowder with $\mathrm{x}=0.6$ contains $\gamma-\mathrm{Fe}_{2} \mathrm{O}_{3}$. Whatever the composition, $\mathrm{Co}^{2+}$ has a strong tendency to occupy tetrahedral sites, contrary to what occurs in bulk ferrites. The nanopowders display a semi conducting behaviour, which varies with temperature. Between ambient and $500{ }^{\circ} \mathrm{C}$, conduction occurs between $\mathrm{Co}^{2+} \leftrightarrow \mathrm{Fe}^{3+}$ pairs, and intergrain conduction predominates. At 
$200{ }^{\circ} \mathrm{C}$ the conductivity is in the $10^{-7} \Omega^{-1} \cdot \mathrm{cm}^{-1}$ range for the different single phased powders. At high temperature $\left(900^{\circ} \mathrm{C}\right)$, the cation distribution is modified and the activation energies are consistent with a polaron mechanism related to $\mathrm{Fe}^{2+} \leftrightarrow \mathrm{Fe}^{3+}$ pairs.

The $\mathrm{Co}_{\mathrm{x}} \mathrm{Fe}_{3-\mathrm{x}} \mathrm{O}_{4}$ nanopowders behave magnetically as a superparamagnetic assembly of single-domain particles. The blocking temperature are mainly related to the particle size, with $\mathrm{T}_{\mathrm{B}}=200 \mathrm{~K}$ for the $4 \mathrm{~nm}$ nanoparticles $(\mathrm{x}=1.8)$. The magnetocrystalline anisotropy constant is significantly higher for these nanoparticles than for bulk ferrites, with $\mathrm{K}=2110^{6} \mathrm{erg} / \mathrm{cm}^{3}$ for $\mathrm{x}=1.8$.

Acknowledgments:

The authors acknowledge the financial support of the France-Tunisia Cooperation Program (CMCU 11/G1301) 


\section{REFERENCES}

[1] Mathew DS, Juang RS. Chem Eng J 2007;129:51. doi:10.1016/j.cej.2006.11.001.

[2] Virden A, Wells S, O’Grady K. J Magn Magn Mater 2007;316:e768. doi:10.1016/j.jmmm.2007.03.100.

[3] Mahmoudi M, Sant S, Wang B, Laurent S, Sen T. Adv Drug Delivery Rev 2011;63:24. doi:10.1016/j.addr.2010.05.006.

[4] Lu X, Liang G, Sun Q,Yang C. Mater Lett 2011;65:674. doi:10.1016/j.matlet.2010.11.066.

[5] Kamble RB, Mathe VL. Sensor Actuat B-Chem 2008;131:205. doi:10.1016/j.snb.2007.11.003.

[6] Darshane SL, Suryavanshi SS, Mulla IS. Ceram Int 2009;35:1793. doi:10.1016/j.ceramint.2008.10.013.

[7] Ajroudi L, Madigou V, Villain S, Mliki N, Leroux Ch. J Cryst Growth 2010;312:2465. doi:10.1016/j.jcrysgro.2010.05.024.

[8] Papa F, Patron L, Carp O, Paraschiv C, Ioan B. J Mol Catal A-Chem 2009;299:93. doi:10.1016/j.molcata.2008.10.036.

[9] Moreira E, Fraga LA, Mendonca MH, Monteiro OC. J Nanopart Res 2012;14:937. doi:10.1007/s11051-012-0937-y.

[10] Spaldin NA, Fiebig M. Science 2005;309:391. doi:10.1126/science.1113357. 
[11] Dho J, Qi X, Kim H, MacManus-Driscoll JI, Blamire MG. Adv Mater 2006;18:1445. doi:10.1002/adma.200502622.

[12] Mørup S, Hansen MF, Frandsen C. Comprehensive Nanoscience and Technology 2011;1:437. doi:10.1016/B978-0-12-374396-1.00036-2.

[13] Pullar RC, Prog Mater Sci 2012;57:1191. doi: 10.1016/j.pmatsci.2012.04.001

[14] Ali SD, Hussain ST, Gilani SR, Appl Surf Sci 2013;271:118. doi:10.1016/j.apsusc.2013.01.140

[15] Leroux Ch, Bendahan M, Madigou V, Ajroudi L, Mliki L, Sensors \& Transducers Journal, to be published april 2014.

[16] Leroux Ch, Bendahan M, Ajroudi L, Madigou V, Mliki N, Proceedings of the International Meeting on Chemicals Sensors, IMCS 2012, Nürnberg, Germany. doi: 10.5162/IMCS2012/P1.8.5

[17] Satyanarayana L, Madhusudan Reddy K, Manorama SV. Mat Chem Phys 2003;82:21. doi:10.1016/S0254-0584(03)00170-6

[18] Murzin DY. Chem Eng Sci 2009;64:1046. doi:10.1016/j.ces.2008.10.066

[19] Rahman AU, Rafiq MA, Karim S, Maaz K, Siddique M, Hasan MM. J Phys D Appl Phys 2011;44:165404. doi:10.1088/0022-3727/44/16/165404.

[20] Sivakumar N, Narayanasamy A, Shinoda K, Chinnasamy CN, Jeyadevan B, Greneche JM. J Appl Phys 2007;102:13916. doi:10.1063/1.2752098.

[21] Bhowmik RN, Naresh N. Int J Eng Sci Techn 2009;2:40. 
[22] Calero-Ddelc VL, Rinaldi C. J Magn Magn Mater 2007;314:60. doi:10.1016/j.jmmm.2006.12.030.

[23] Meaz TM, Amer MA and El-Nimr MK. Egypt J Solids 2008;31:147.

[24] Gopalan EV, Joy PA, Al-Omari IA, Kumar DS, Yoshida Y, Anantharaman MR. J Alloy Compd 2009;485:711. doi:10.1016/j.jallcom.2009.06.033.

[25] Gabal MA, Ata-Allah SS. J Phys Chem Solids 2004;65:995. doi:10.1016/j.jpcs.2003.10.059

[26] Gul IH, Maqsood A, Naeem M, Naeem Ashiq M. J Alloy Compd 2010;507:201. doi:10.1016/j.jallcom.2010.07.155.

[27] Antic B, Perovic M, Kremenovic A, Blanusa J, Spasojevic V, Vulic P, Bessais L and Bozin ES. J Phys Condens Mat 2013;25:086001. doi: 10.1088/0953-8984/25/8/086001

[28] Lee DH, Kim HS, Lee JY, Yo CH, Kim KH. Solid State Commun 1995;96:445.

[29] Javed T, Asghari Maqsood A, Malik AA. J Supercond Nov Magn 2011;24:2137. $10.1007 / \mathrm{s} 10948-011-1168-7$.

[30] Ferreira TAS, Waerenborgh JC, Mendonça MHRM, Nunes MR, Costa FM. Sol State Sci 2003;5:383. doi:10.1016/S1293-2558(03)00011-6

[31] Le Trong H , Barnabe A, Presmanes L, Tailhades Ph. Solid State Sci 2008;10:550. doi:10.1016/j.solidstatesciences.2007.10.004.

[32] Carta D, Casula MF, Falqui A, Loche D, Mountjoy G, Sangregorio C and Corrias A. J Phys Chem C 2009;113:8606. doi:10.1021/jp901077c. 
[33] Kumar L, Kumar P, Kar M. J Alloy Compd 2013;551:72. doi:10.1016/j.jallcom.2012.10.009.

[34] CaRine crystallography Boudias C, Monceau D, 1989-2004, http://pro.wanadoo.fr/carine.crystallography

[35] Turquat Ch, Leroux Ch, Gloter A, Serin V and Nihoul G. Int J Inorg Mater 2001;3:1025.

[36] Zhao L, Zhang H, Xing Y, Song S, Yu S, Shi W, Guo X, Yang J, Lei Y, Cao F. J Solid State Chem 2008;181:245. doi:10.1016/j.jssc.2007.10.034.

[37] Navard P, Haudin JM. J Therm Anal Calorim 1984;29:405.

[38] Cornell RM, Schwertmann U. The iron oxides, second ed.:Wiley-Verlag; 2003.

[39] Panneer Muthuselvam I, Bhowmik RN. Solid State Sci 2009;11:719. doi:10.1016/j.solidstatesciences.2008.10.012

[40] Shoar Abouzari MR, Berkemeier F, Schmitz G and Wilmer D. Solid State Ionics 2009;180:922. doi:10.1016/j.ssi.2009.04.002.

[41] Jonker GH. J Phys Chem Sol 1959;9:165.

[42] Emin D, Huang Liu NL. Phys Rev B 1983;27:4788.

[43] Verwey EJW, Haayman PW, Romeyn FC, Van Oosterhout GW. Philips Research Reports 1950;5:173.

[44] Hosseinpour A, Sadeghi H, Morisako A. J Magn Magn Mater 2007;316:e283. doi:10.1016/j.jmmm.2007.02.119 
[45] Bensebaa F, Zavaliche F, L'Ecuyer P, Cochrane RW, Veres T, J Colloid Interf Sci 2004;277:104. doi:10.1016/j.jcis.2004.04.016

[46] Betancourt-Galindo R, Ayala-Valenzuela O, Garcı-Cerda LA, Rodrıguez-Fernandez O, Matutes-Aquino J, Ramos G,Yee-Madeira H. J Magn Magn Mater 2005;294:e33. doi:10.1016/j.jmmm.2005.03.050

[47] Franco Jr A, Zapf V, J Magn Magn Mater 2008;320:709. doi:10.1016/j.jmmm.2007.08.009

[48] Ammar S, Helfen A, Jouini N, Fiévet F, Villain F, Rosenman I, Danot M, Molinié P. J Mater Chem 2001;11:186. doi: 10.1039/B003193N

[49] Ahn Y, Choi EJ , Kim S, Ok HN. Mater Lett 2001;50:47.

[50] Tung LD, Kolesnichenko V, Caruntu D, Chou NH, O’Connor CJ and Spinu L. J Appl Phys 2003;93:10. doi:10.1063/1.1540145.

[51] Biswal D, Peeples BN, Peeples C, Pradhan AK. J Magn Magn Mater 2013;345:1. doi:10.1016/j.jmmm.2013.05.052

[52] Song Q, Zhang ZJ. J Am Chem Soc 2004;126:6164. doi: 10.1021/ja049931r

[53] Maaz K, Mumtaz A, Hasanain SK, Ceylan A. J Magn Magn Mater 2007;308:289. doi:10.1016/j.jmmm.2006.06.003

[54] Bean C and Livingston J. J Appl Phys 1959;30:1205.

[55] Liu C, Zou B, Rondinone AJ and Zhang ZJ. J Am Chem Soc 2000;122:6263. 
[56] Vaishnava PP, Senaratne U, Buc E, Naik R, Naik VM, Tsoi G, Wengerand LE, Boolchand P. J Appl Phys 2006;99:702.

doi: $10.1063 / 1.2165922$

[57] Ben Tahar L, Artus M, Ammar S, Smiri LS, Herbst F, Vaulay MJ, Richard V, Grenèche

JM, Villain F, Fiévet F. J Magn Magn Mater 2008;320:3242. doi:10.1016/j.jmmm.2008.06.031

[58] Néel L, Ann Géophys 1949;5:99.

[59] Brown WF. Phys Rev 1963;130:1677.

[60] Moumen N and Pileni MP. J Phys Chem 1996;100:1867.

[61] Chen JP,Sorensen CM,Klabunde KJ and Hadjipanayis GC .J. Appl. Phys 1994; 76 :6316

[62] Poddar P, Telem-Shafir T, Fried T, Markovich G. Phys Rev B 2002;66:060403. 